\title{
Optimal Sequence in General Flow Shop with Job Block Criteria using Fuzzy Index Technique
}

\author{
Arti Tyagi, Ashima Kalra, Cheshta Kashyap
}

\begin{abstract}
Here, we are finding a novel methodology to solve a problem of scheduling of general flow shop where proceeding time of job is indeterminate. The parameters required to solve such problem was considered to be in triangular fuzzy number. The concept of job block concept has been introduced to understand relative interference of one job with other. The novelty of this method lies in the section that it will not convert the fuzzy processing time into classical numbers to figure out the near optimal sequence of jobs. The method has been made clearer by giving a numerical example to demonstrate the purposed technique.
\end{abstract}

Index Terms: Triangular fuzzy number (TFN), Fuzzy processing time, Flow shop, Fuzzy ranking, Location index etc.

\section{INTRODUCTION}

Scheduling is very crucial in a production method or in any multifarious system. It is required in variety of domains such as institutes, hospitals, airlines, trains, company etc. The scheduling techniques can also act as a decision maker in various cases such as; the duration for which operators remain idle to utilize that time for some other task; in industry or in business can be utilized in a cost-effective way. In flow shop scheduling, our objective is to form a series of jobs i.e.to process machines in a pre-defined order or to find some well-defined criteria; such as minimization of make span or total time elapsed, production cost, rental cost of machines, mean flow time, idle time or satisfaction level of element maker etc.

A Heuristic procedure was first introduced by [1] Johnson for flow shop scheduling in two and restrictive 3 stage problems to reduce the total elapsed time for completion of all the jobs. [2] Gupta J.N.D. and Dudek had done an experimental study inclusive of measurement of its performance in flow shop scheduling. The study endorses the utilization of blend of measures like make span and total flow time in order to minimize the cost of scheduling. [3] Maggu and Dass gave the idea of equivalent job for a job block giving priority of one job over another in production scheduling. [4] Singh T.P. added various practical concepts in scheduling theory making problems to be more significant and wider. But all these researchers have assumed the processing time and set up time of jobs, deterministic in nature.

In literature there were varieties of fuzzy methods for the problem of flow shop scheduling. [5] Maccahon and Lee were first to introduce the method of job sequencing with fuzzy

Revised Manuscript Received on june,15 2019

Arti Tyagi Chandigarh Group of colleges, Landran, Panjab, India Ashima Kalra, PhD Research scholar,IK Gujral PTU,Jalandhar, India Cheshta Kashyap, Maharishi Markandeshwar University, Sadopur, Ambala, Haryana. processing time. [6] Ishibuchi etal and [7] Hong etal. offered a new triangular fuzzy Johnson algorithm. [8] S. Reza Hejari etal then proposed an enhanced version of McMahon \& Lee algorithm. Most of the authors have applied [9] Yager's formulae to defuzzify the processing time in their study. In this paper we have apply the fuzziness indexing technique in a general $\mathrm{m}$ stage flow shop scheduling with triangular fuzzy parameters. The results appear fairly good. The idea of corresponding job for a job block has also been included. By applying a new type of fuzzy arithmetic and a fuzzy ranking method using location index, the results have been derived through fuzziness index function technique given by [10] Ming Ma etal . In this technique, there is no need to convert the fuzzy processing time into classical numbers, differing with the work of Yager's (1981) and other authors.

[11], [12], [13], [14], [15], [16] T.P. Singh etal explored a lot of scheduling models under fuzzy environments and extended the scheduling research in fuzzy system with applications.

Recently [17] Arti and Namita applied the fuzzy index function techniques in $\mathrm{n}$ jobs 3 stage scheduling problem. The present research is further an addition to this work.

The purposed study is made clear through numerical example.

\section{PRELIMINARIES:}

In this section we give some notions and results which were used in further study

\section{A. FUZZY SET:-}

A fuzzy set $\tilde{\mathrm{A}}$ is defined by $\tilde{\mathrm{A}}=\left\{\left(x, \mu_{\tilde{\mathrm{A}}}(x)\right): x \in \mathrm{X}, \mu_{\tilde{\mathrm{A}}}(x) \in[0\right.$, $1]\}$. In the pair $\left\{\left(x, \mu_{\tilde{A}}(x)\right)\right\}$, the element $\mathrm{x}$ belongs to the classical set $\mathrm{A}$, whereas the other element $\mu_{\tilde{\mathrm{A}}}(x)$, belongs to the interval $[0,1]$, termed as membership function or grade of membership.

Zadeh L.A. [1965] introduces fuzzy set as an addition to the classical notation of set.

\section{B. FUZZY NUMBER:}

A fuzzy set $\tilde{A}$ defined with the help of set of real numbers $R$ is termed as fuzzy number if its membership functions $\tilde{\mathrm{A}}: \mathrm{R} \rightarrow[0,1]$ fulfill the following study.

(a) $\tilde{\mathrm{A}}$ is convex, $\tilde{\mathrm{A}}\left\{\lambda \mathrm{x}_{1}+(1-\mathrm{t}) \mathrm{x}_{2}\right\}=\min \left\{\tilde{\mathrm{A}}\left(\mathrm{x}_{1}\right), \tilde{\mathrm{A}}\right.$ $\left.\left(\mathrm{x}_{2}\right)\right\}$, for all $\mathrm{x}_{1}, \mathrm{x}_{2} \in \mathrm{R}$ and $\lambda \in[0,1]$

(b) $\tilde{\mathrm{A}}$ is normal i.e. there exists an $\mathrm{x} \in \mathrm{R}$ such that $\tilde{\mathrm{A}}$ $(\mathrm{x})=1$

(c) $\tilde{\mathrm{A}}$ is piecewise continuous. 


\section{TRIANGULAR FUZZY NUMBER (TFN):}

Any fuzzy number ã defined on R, called as a triangular fuzzy number (TFN) or linear fuzzy number only if its membership functions is given by ã: $\mathrm{R} \rightarrow[0,1]$ has the following features:

$\tilde{a}(\mathrm{x})=\left\{\begin{array}{c}\frac{\mathrm{x}-\mathrm{a}_{1}}{\mathrm{a}_{2}-\mathrm{a}_{1}}, \text { for } \mathrm{a}_{1} \leq \mathrm{x} \leq \mathrm{a}_{2} \\ \frac{\mathrm{a}_{3}-\mathrm{x}}{\mathrm{a}_{3}-\mathrm{a}_{2}}, \text { for } \mathrm{a}_{2} \leq \mathrm{x} \leq \mathrm{a}_{3} \\ 0, \text { elsewhere }\end{array}\right.$

The parameters $\left(a_{1}, a_{2}, a_{3}\right)$ with $\left(a_{1}<a_{2}<a_{3}\right)$ determine $x$ coordinates of three corners of underlying triangular $\mathrm{M} \mathrm{F}$.

(a) Fuzzy numbers is denoted by $\tilde{a}=\left(a_{1}, a_{2}, a_{3}\right)$. We use $F(R)$ to represent the set of all triangular fuzzy numbers.

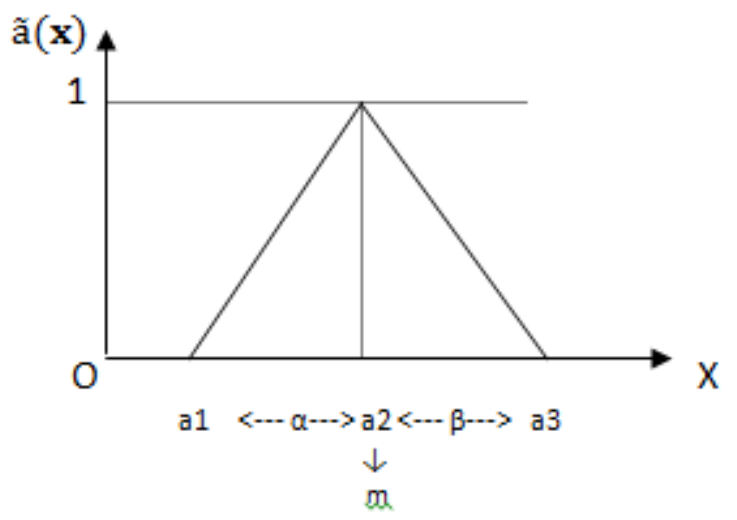

Fig 1: Triangular fuzzy number $\tilde{\mathbf{a}}=\left(\mathbf{a}_{1}, \mathbf{a}_{2}, \mathbf{a}_{3}\right)=(\alpha, \mathbf{m}, \beta)$.

If $\mathrm{m}=\mathrm{a}_{2}$ symbolizes the modal value or midpoint, $\alpha=\left(\mathrm{a}_{2}-\mathrm{a}_{1}\right)$ denotes the left spread and $\beta=\left(a_{3}-a_{2}\right)$ characterizes the right spread of the triangular fuzzy number $\tilde{a}=\left(a_{1}, a_{2}, a_{3}\right)$, then the triangular fuzzy number $\tilde{a}$ can be given with the triple $\tilde{\mathrm{a}}=\left(\mathrm{a}_{1}, \mathrm{a}_{2}, \mathrm{a}_{3}\right)=(\alpha, \mathrm{m}, \beta)$.

(b) A triangular fuzzy number ã $\epsilon \mathrm{F}(\mathrm{R})$ can also be denoted as a pair; $\tilde{a}=(\underline{a}, \overline{\mathbf{a}})$ of functions and $\underline{a}(\mathrm{r})$ and $\overline{\mathbf{a}}(\mathbf{r})$ for $0 \leq \mathrm{r} \leq 1$ which fulfills the following conditions:

(i) $\underline{\mathbf{a}}(\mathbf{r})$ is a bounded monotonic increasing left continuous function.

(ii) $\overline{\mathbf{a}}(\mathbf{r})$ is a bounded monotonic decreasing left continuous function.

(iii) $\underline{\mathbf{a}}(\mathbf{r}) \leq \overline{\mathbf{a}}(\mathbf{r}), 0 \leq \mathrm{r} \leq 1$

\section{LOCATION INDEX:}

For any random triangular fuzzy number $\tilde{a}=(\underline{\mathbf{a}}, \overline{\mathbf{a}})$, the number $\mathrm{a}_{0}=\left(\frac{\mathrm{a}(1)+\bar{a}(1)}{2}\right)$ is called as location index number of ã. The two non-decreasing left continuous functions $\mathrm{a}_{*}=$ $\left(\mathrm{a}_{0}-\mathbf{a}\right), \mathrm{a}^{*}=\left(\overline{\mathbf{a}}-\mathrm{a}_{0}\right)$ were said to be left fuzziness index function as well as right fuzziness index function respectively. Therefore every triangular fuzzy number $\tilde{a}=\left(a_{1}, a_{2}, a_{3}\right)$ can also be symbolized by $\tilde{a}=\left(a_{0}, a_{*}, a^{*}\right)$

\section{E. RANKING OF TRIANGULAR FUZZY NUMBERS}

Many different methodologies were given in the literature for the ranking of fuzzy numbers. [18] Abbas bandy and Hajjari offered a novel method of ranking which is centered on the left and the right ranges at some $\alpha$-levels of fuzzy numbers.
For an arbitrary triangular fuzzy number $\tilde{a}=\left(a_{1}, a_{2}, a_{3}\right)$ $=\left(\mathrm{a}_{0}, \mathrm{a}_{*}, \mathrm{a}^{*}\right)$ with parametric form $\tilde{\mathrm{a}}=(\underline{\mathbf{a}}(\mathbf{r}), \overline{\mathbf{a}}(\mathbf{r}))$, we state the value of the triangular fuzzy number ã by

$$
\begin{gathered}
\operatorname{Mag}(\tilde{\mathbf{a}})=\frac{1}{2}\left(\int_{0}^{1}\left(\underline{\mathbf{a}}+\overline{\mathbf{a}}+\mathbf{a}_{0}\right) \mathbf{f}(\mathbf{r}) \mathbf{d r}\right) \\
=\frac{1}{2}\left(\int_{0}^{1}\left(\mathbf{a}^{*}+4 \mathbf{a}_{0}-\mathbf{a}_{8}\right) \mathbf{f}(\mathbf{r}) \mathbf{d r}\right) .
\end{gathered}
$$

Where the function $f(r)$ is a non-negative and growing function in interval $[0,1]$ with $f(0)=0, \quad f(1)=1$ and $\int_{0}^{1} f(r) d r=\frac{1}{2}$. The function $\mathrm{f}(\mathrm{r})$ can also be deliberated as a weighting function. In real world problems, $\mathrm{f}(\mathrm{r})$ can be selected by the decision maker according to the situation. In present research, for our suitability we refer $f(r)=r$.

So the magnitude of a triangular fuzzy number ã is:

$$
\operatorname{Mag}(\tilde{a})=\left(\frac{a^{*}+4 a_{0}-a_{4}}{4}\right) \text {. }
$$

The magnitude of a triangular fuzzy number ã provides the data about every membership degree, and significance of this magnitude is pictorial and normal. Mag (ã) is used to rank fuzzy numbers, Larger the Mag (ã) larger is the fuzzy number. For any two triangular fuzzy numbers $\tilde{a}=\left(\mathrm{a}_{0}, \mathrm{a}_{*}, \mathrm{a}^{*}\right)$ and $\widetilde{b}=\left(b_{0}, b_{*}, b^{*}\right)$ in $F(R)$, we can define the ranking of $\tilde{a}$ and $\tilde{\mathrm{b}}$ on the basis of the $\operatorname{Mag}(\tilde{\mathrm{a}})$ and $\operatorname{Mag}(\tilde{\mathrm{b}})$ on $\mathrm{R}$ as follows:
(i) $\tilde{\mathrm{a}} \geq \widetilde{\mathrm{b}}$ if and only if $\operatorname{Mag}(\tilde{\mathrm{a}}) \geq \operatorname{Mag}(\tilde{\mathrm{b}})$
(ii) $\tilde{\mathrm{a}} \leq \tilde{\mathrm{b}}$ if and only if $\operatorname{Mag}(\tilde{\mathrm{a}}) \leq \operatorname{Mag}(\tilde{\mathrm{b}})$
(iii) $\tilde{\mathrm{a}} \approx \widetilde{\mathrm{b}}$ if and only if $\operatorname{Mag}(\tilde{\mathrm{a}})=\operatorname{Mag}(\tilde{\mathrm{b}})$

\section{F. SYMMETRIC TFN:}

A triangular fuzzy number $\tilde{\mathrm{a}}=\left(\mathrm{a}_{0}, \mathrm{a}_{*}, \mathrm{a}^{*}\right)$ is said to be symmetric if $a_{*}=a^{*}$.

\section{(a) POSITIVE FUZZY NUMBER:}

A triangular fuzzy number $\tilde{a}=\left(a_{0}, a_{*}, a^{*}\right)$ is termed as non-negative in the only case if Mag ( $\mathbf{a}) \geq 0$ and is denoted by $\tilde{\mathbf{a}} \geq \widetilde{\mathbf{0}}$. Further if Mag $(\tilde{\mathbf{a}})>0$, then $\tilde{a}=\left(\mathrm{a}_{0}, \mathrm{a}_{*}, \mathrm{a}^{*}\right)$ is called as a positive fuzzy number and is denoted by $\tilde{\mathbf{a}}>\widetilde{\mathbf{0}}$

\section{G. EQUIVALENT FUZZY NUMBERS:}

Two triangular fuzzy numbers $\tilde{a}=\left(a_{0}, a_{*}, a^{*}\right)$ and $\tilde{\mathbf{b}}=\left(\mathrm{b}_{0}, \mathrm{~b}_{*}, \mathrm{~b}^{*}\right)$ in $\mathrm{F}(\mathrm{R})$ are termed as comparable if and only if

$$
\operatorname{Mag}(\tilde{\mathbf{a}})=\operatorname{Mag}(\tilde{\mathrm{b}}) \text {. }
$$

That is $\tilde{\mathbf{a}} \approx \widetilde{\mathbf{b}}$ if and only if $\operatorname{Mag}(\tilde{\mathbf{a}})=\operatorname{Mag}(\tilde{\mathbf{b}})$. Two triangular fuzzy numbers $\tilde{a}=\left(a_{0}, a_{*}, a^{*}\right)$ and $\widetilde{b}=\left(b_{0}\right.$, $\left.b_{*}, b^{*}\right)$ in $F(R)$ are said to be equal if and only if $a_{0}=b_{0}$, $\mathrm{a}_{*}=\mathrm{b}_{*}, \mathrm{a}^{*}=\mathrm{b}^{*}$. That is $\tilde{\mathrm{a}} \approx \widetilde{\mathrm{b}}$ if and only if $\mathrm{a}_{0}=\mathrm{b}_{0}, \mathrm{a}_{*}=\mathrm{b}_{*}$, $a^{*}=b^{*}$.

\section{H. ARITHMETIC OPERATIONS ON TRIANGULAR FUZZY NUMBERS}

Ming Ma et al. (1999) have introduced a new fuzzy arithmetic on the basis of both location index function and fuzziness index function.

The location index number is considered in the ordinary 
arithmetic, while the fuzziness index function were supposed to follow the lattice rule which is least upper bound in the lattice $L$. that is for $a, b \in L$ we define $a \vee b=\max \{a, b\}$ and $\mathrm{a} \wedge \mathrm{b}=\min \{\mathrm{a}, \mathrm{b}\}$.

For any triangular fuzzy numbers $\tilde{a}=\left(a_{0}, a_{*}, a^{*}\right)$ and $\widetilde{\mathrm{b}}=\left(\mathrm{b}_{0}, \mathrm{~b}_{*}, \mathrm{~b}^{*}\right)$ and $*=\{+,-, \mathrm{x}, \div\}$, the arithmetic operations on the triangular fuzzy numbers are defined by $\tilde{\mathrm{a}} * \tilde{\mathrm{b}}=\left(\mathrm{a}_{0} * \mathrm{~b}_{0}, \mathrm{a} * \mathrm{v} \mathrm{b}_{*}, \mathrm{a}^{*} \mathrm{v} \mathrm{b}^{*}\right)$.

In specific case; for any two triangular fuzzy numbers $\tilde{a}=\left(a_{0}, a_{*}, a^{*}\right)$ and $\tilde{b}=\left(b_{0}, b_{*}, b^{*}\right)$, we define

(i) Addition: $\widetilde{\mathrm{a}}+\widetilde{\mathrm{b}}=\left(\mathrm{a}_{0}, \mathrm{a}_{*}, \mathrm{a}^{*}\right)+\left(\mathrm{b}_{0}, \mathrm{~b}_{*}, \mathrm{~b}^{*}\right)=\left(\mathrm{a}_{0}+\right.$ $\left.\mathrm{b}_{0}, \max \left\{\mathrm{a}_{*}, \mathrm{~b}_{*}\right\}, \max \left\{\mathrm{a}^{*}, \mathrm{~b}^{*}\right\}\right)$

(ii) Subtraction: $\widetilde{\mathrm{a}}-\widetilde{\mathrm{b}}=\left(\mathrm{a}_{0}, \mathrm{a}_{*}, \mathrm{a}^{*}\right)-\left(\mathrm{b}_{0}, \mathrm{~b}_{*}, \mathrm{~b}^{*}\right)=\left(\mathrm{a}_{0}-\right.$ $\left.b_{0}, \max \left\{a_{*}, b_{*}\right\}, \max \left\{a^{*}, b^{*}\right\}\right)$

(iii) Multiplication: $\quad \widetilde{\mathrm{a}} \times \widetilde{\mathrm{b}}=\left(\mathrm{a}_{0}, \mathrm{a}_{*}, \mathrm{a}^{*}\right) \quad \times$ $\left(b_{0}, b_{*}, b^{*}\right)=\left(a_{0} \times b_{0}, \max \left\{a_{*}, b_{*}\right\}, \max \left\{a^{*}, b^{*}\right\}\right)$

(iv) Division: $\widetilde{\mathrm{a}} \div \widetilde{\mathrm{b}}=\left(\mathrm{a}_{0}, \mathrm{a}_{*}, \mathrm{a}^{*}\right) \div\left(\mathrm{b}_{0}, \mathrm{~b}_{*}, \mathrm{~b}^{*}\right)=\left(\mathrm{a}_{0} \div\right.$ $\left.\mathrm{b}_{0}, \max \{\mathrm{a} * \mathrm{~b} *\}, \max \left\{\mathrm{a}^{*}, \mathrm{~b}^{*}\right\}\right)$

\section{METHODOLOGY}

This section Deals with some notations, assumptions, Method and Procedure to solve a problem.

\section{A. ASSUMPTIONS}

(a) No job anticipation is permitted.

(b) The machine can only execute one job at a time.

(c) All jobs are offered at the commencement of the scheduling time horizon.

(d) Each job has m operations.

(e)Each job must be accomplished once it is initiated.

\section{B. EQUIVALENT JOB THEOREM FOR JOB BLOCK:}

We consider the job block $(\alpha k, \alpha m)$ having processing time $\left(A_{c k}, A_{c m}\right)$ is corresponding to single job $\beta$ (called equivalent job). The treating time of job $\beta$ on machines are given by Maggu and Das (1977) in equivalent job block theorem as,

$$
\begin{gathered}
A_{\beta}=A_{\alpha k}+A_{c m}-\min \left(B_{\alpha k}, A_{\alpha m}\right) \\
B_{\beta}=B_{\alpha k}+B_{\alpha m}-\min \left(B_{\alpha k}, A_{\alpha m}\right)
\end{gathered}
$$

Job block $(\alpha \mathrm{k}, \alpha \mathrm{m})$ implies that job $\alpha \mathrm{k}$ is preferred over $\alpha \mathrm{m}$ and in the order $\alpha \mathrm{k}, \alpha \mathrm{m}$.

\section{NOTATIONS}

$\mathrm{S}_{\mathrm{k}}$ : Sequence obtained on application of Johnson's procedure, $\mathrm{k}=1,2,3, \ldots \ldots, \mathrm{m}$.

$\mathrm{M}_{\mathrm{j}}$ : Machine $\mathrm{j}, \mathrm{j}=1,2,3, \ldots \ldots, \mathrm{m}$.

$\widetilde{M}$ : Minimum makes span

$\widetilde{A_{2 J}}$ : Fuzzy processing time of $\mathrm{i}^{\text {th }}$ job on machine $\mathrm{M}_{\mathrm{j}}$, $\mathrm{I}=1,2,3, \ldots \ldots \ldots, \mathrm{n} ; \mathrm{j}=1,2,3, \ldots \ldots ., \mathrm{m}$.

$\widetilde{t_{i j}}\left(\mathrm{~S}_{\mathrm{k}}\right)$ : Completion time of $\mathrm{i}^{\text {th }}$ job of sequence $\mathrm{S}_{\mathrm{k}}$ on machine $\mathrm{M}_{\mathrm{j}}$.

$\widetilde{I_{u j}}\left(\mathrm{~S}_{\mathrm{k}}\right)$ : Idle time of machine $\mathrm{M}_{\mathrm{j}}$ for job $\mathrm{i}$ in the sequence $\left(S_{k}\right)$
$\tilde{U}_{J}\left(\mathrm{~S}_{\mathrm{k}}\right)$ :Utilization time for which machine $\mathrm{M}_{\mathrm{j}}$ is required

$\beta \rightarrow$ Equivalent job for job block

$\tilde{C} T\left(\mathrm{~S}_{\mathrm{i}}\right)$ : Total completion time of the jobs for sequence $S_{i}$

\section{PROBLEM FORMULATION}

Suppose some job i $(\mathrm{i}=1,2,3, \ldots \ldots, n)$ is to be done on $\mathrm{j}$ machines $j=(1,2, \ldots ., m)$ with the condition $(\alpha k, \alpha m)$ as a job block. Let $\widetilde{A_{u j}}$ be the processing time of $\mathrm{i}^{\text {th }}$ job on $\mathrm{j}^{\text {th }}$ machine defined by triangular fuzzy numbers. Our objective is to figure out the sequence $\left\{S_{\mathrm{k}}\right\}$ of the jobs which reduce the make duration of machines i.e. Our target is to reduce the net pass by time on machines when minimizing their utilization time is subject to constraints of equivalent job for job block .

\section{E. ALGORITHM}

Algorithm for heuristic approach was build up to minimize the utilization time and hence scheduling along with processing time in fuzzy environment.

Let there are $m$ machines $\mathbf{M}_{1}, \mathbf{M}_{2}, \ldots \ldots, \mathbf{M}_{\mathrm{m}}$. This problem can be converted to a two machine problem, if one of the following conditions is fulfilled.

Let $\widetilde{A_{a 1}}, \widetilde{A_{a 2}}, \ldots \ldots . \widetilde{A_{u m}}$ be the processing times on machines $\mathrm{M}_{1}, \mathrm{M}_{2}, \ldots \ldots, \mathrm{M}_{\mathrm{m}}$ respectively.

$$
\begin{aligned}
& \min _{i} \widetilde{A_{i 1}} \geq \max _{i} \widetilde{A_{i j}}, j= \\
& 2,3, \ldots, m-1 \\
& 2,3, \ldots \ldots, m-1
\end{aligned}
$$

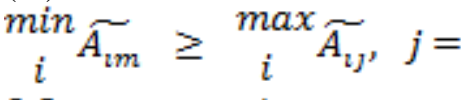

Then the problem can be converted to a two machine problem. Introduce two fictitious machines $\mathrm{G}$ and $\mathrm{H}$ such that

$$
\begin{aligned}
& \frac{\widetilde{G}}{A_{a 1}}+\widetilde{A_{a 2}}+\widetilde{A_{u 3}}+\ldots . . .+\widetilde{A_{u(m-1)}}, i= \\
& 1,2,3, \ldots, n \\
& \widetilde{H_{2}}=\widetilde{A_{12}}+\widetilde{A_{13}}+\widetilde{A_{14}}+\ldots \ldots+\widetilde{A_{u m}}, i=
\end{aligned}
$$

Where $\widetilde{G}_{2}$ and $\widetilde{H}_{2}$ are the processing times for job $i$ on machines $\mathrm{G}$ and $\mathrm{H}$ respectively.

Obtain the sequence $S_{\mathrm{k}}$ (say) by applying [1] Johnson's (1954) algorithm on machines G \& H and apply equivalent job block theorem. 


\section{NUMERICAL ILLUSYTRATION}

Imagine 5 jobs, 3 machines flow shop problem whose processing time was given by triangular fuzzy numbers as given on table 1 . Equivalent job $\beta$ for job block $\beta=(1,5)$ i.e. jobs 1 and 5 are held as a job block. Our aim is to find an optimum schedule to diminish the net elapsed time of the machines.

Table 1: Fuzzy Processing Times $\tilde{\mathbf{a}}=\left(\mathbf{a}_{1}, \mathbf{a}_{2}, \mathbf{a}_{3}\right)$

\begin{tabular}{|c|c|c|c|c|}
\hline Job & $\mathbf{M}_{1}$ & $\mathbf{M}_{2}$ & $\mathbf{M}_{3}$ & $\mathbf{M}_{4}$ \\
\hline $\mathbf{l}$ & $(14,16,18)$ & $(10,12,14)$ & $(7,8,9)$ & $(4,5,6)$ \\
$\mathbf{2}$ & $(14,15,16)$ & $(11,12,13)$ & $(8,9,10)$ & $(5,6,7)$ \\
$\mathbf{3}$ & $(17,18,19)$ & $(12,13,14)$ & $(9,10,11)$ & $(6,7,8)$ \\
$\mathbf{4}$ & $(16,17,18)$ & $(11,13,15)$ & $(10,11,12)$ & $(7,8,9)$ \\
$\mathbf{5}$ & $(13,14,15)$ & $(10,11,12)$ & $(7,9,11)$ & $(4,6,8)$ \\
\hline
\end{tabular}

\section{A. SOLUTION:-}

In the given scheduling problems, all the decision parameters are represented using triangular fuzzy numbers in the form of $\tilde{a}=\left(a_{1}, a_{2}, a_{3}\right)$. As per definition 2.4 , these numbers can also be represented in convenient form

$\tilde{\mathrm{a}}=\left(\mathrm{a}_{1}, \mathrm{a}_{2}, \mathrm{a}_{3}\right)=\left(\mathrm{a}_{0}, \mathrm{a}_{*}, \mathrm{a}^{*}\right)$ where $\mathrm{a} *=\left(\mathrm{a}_{0^{-}} \mathrm{a}\right) \rightarrow$ left fuzziness index function of ã respectively. Now for machine $M_{1}$ and job 1 , the processing time can be calculated as,

$\frac{x-a_{0}}{a_{4}-a_{0}}=\alpha$

$\Rightarrow \mathrm{x}-\mathrm{a}_{0}=\alpha\left(\mathrm{a}_{*}-\mathrm{a}_{0}\right)=>\mathrm{x}=\alpha\left(\mathrm{a}_{*}-\mathrm{a}_{0}\right)+\mathrm{a}_{0} \rightarrow \overline{\mathbf{a}}(\mathbf{r})$

Also $\frac{\mathrm{a}^{*}-\mathrm{x}}{\mathrm{a}^{*}-\mathrm{a}_{4}}=\boldsymbol{\alpha}$

$=>a^{*}-x=\alpha\left(a^{*}-a_{*}\right)$

$\Rightarrow \mathrm{x}=\mathrm{a}^{*}-\alpha\left(\mathrm{a}^{*}-\mathrm{a}_{0}\right) \rightarrow \overline{\mathbf{a}}(\mathbf{r})$

Take e.g. processing time $(12,13,14)$ we have

$\frac{\mathrm{x}-12}{13-12}=\alpha=>\mathrm{x}=\alpha+12 \rightarrow \underline{\mathrm{a}}=13$ for $\alpha=1$

Or $\frac{14-\mathrm{x}}{14-13}=\alpha=>\mathrm{x}=14-\alpha \rightarrow \overline{\mathrm{a}}=13$ for $\alpha=1$

$\therefore \tilde{\mathrm{a}}=(12,13,14) \approx(13,1,1)$

The given data of table 1 in form of $\tilde{a}=\left(a_{0}, a_{*}, a^{*}\right)$ with the help of index function can be presented in table 2 as:

Table 2: Fuzzy Processing time $\tilde{a}=\left(\left\langle\mathbf{a}_{0}, \mathbf{a}_{*}, \mathbf{a}^{*}\right\rangle\right)$

\begin{tabular}{|c|c|c|c|c|}
\hline Jobs & $\mathrm{M}_{1}$ & $\mathrm{M}_{2}$ & $\mathrm{M}_{5}$ & $\mathrm{M}_{4}$ \\
\hline 1 & $\langle 16,2,2\rangle$ & $\langle 12,2,2\rangle$ & $\langle 8,1,1\rangle$ & $\langle 5,1,1\rangle$ \\
2 & $\langle 17,1,1\rangle$ & $\langle 12,1,1\rangle$ & $\langle 9,1,1\rangle$ & $\langle 6,1,1\rangle$ \\
3 & $\langle 18,1,1\rangle$ & $\langle 13,1,1\rangle$ & $\langle 10,1,1\rangle$ & $\langle 7,1,1\rangle$ \\
\multirow{2}{*}{4} & $\langle 15,1,1\rangle$ & $\langle 13,2,2\rangle$ & $\langle 11,1,1\rangle$ & $\langle 8,1,1\rangle$ \\
5 & $\langle 14,1,1\rangle$ & $\langle 11,1,1\rangle$ & $\langle 9,2,2\rangle$ & $\langle 6,2,2\rangle$ \\
\hline
\end{tabular}

Minimum Processing time on $\mathrm{M}_{1}=\langle 14,1,1\rangle$ Maximum Processing time on $\mathrm{M}_{2}=\langle 13,2,2\rangle$

Minimum Processing time on $\mathrm{M}_{3}=\langle 8,1,1\rangle$

Clear, Min Processing of $\mathrm{M}_{1} \geq$ Maximum Processing time of $\mathrm{M}_{2}$

As from section II (E), $\operatorname{mag}(\tilde{a})=\frac{a+4 a_{0}-a_{8}}{4}$

$\operatorname{mag}(\tilde{\mathrm{a}})$ on $\mathrm{M}_{1}=\frac{1+4 \times 13-1}{4}=14$

$\operatorname{mag}(\tilde{a})$ on $M_{2}=\frac{2+4 \times 12-2}{4}=13$

Convert the problem in two fictitious machines $\mathrm{G}$ and $\mathrm{H}$ such that

$$
\begin{aligned}
& \widetilde{G_{2}}=\widetilde{M_{11}}+\widetilde{M_{22}}+\widetilde{M_{13}}+\widetilde{M_{u 4}} \\
& \widetilde{H_{2}}=\widetilde{M_{12}}+\widetilde{M_{13}}+\widetilde{M}_{u 4}
\end{aligned}
$$

and represent the data in table 3 as follows:

\section{$\underline{\text { Table } 3}$}

\begin{tabular}{|c|c|c|}
\hline Jobs & G & H \\
\hline 1 & $\langle 36,2,2\rangle$ & $\langle 25,2,2\rangle$ \\
2 & $\langle 38,1,1\rangle$ & $\langle 27,1,1\rangle$ \\
3 & $\langle 41,1,1\rangle$ & $\langle 30,1,1\rangle$ \\
4 & $\langle 39,2,2\rangle$ & $\langle 32,1,1\rangle$ \\
5 & $\langle 34,2,2\rangle$ & $\langle 26,2,2\rangle$ \\
\hline
\end{tabular}

Given equivalent job $\beta=(1,5)$ for job block on applying equivalent job block theorem, we get

$$
\begin{aligned}
& \mathrm{G}_{\beta}=\langle 51,2,2\rangle \\
& \mathrm{H}_{\beta}=\langle 23,2,2\rangle
\end{aligned}
$$

the processing time on $\mathrm{G}$ and $\mathrm{H}$ in given in table 4 .

\section{Table 4: Processing time on $G$ and $H$}

\begin{tabular}{|c|c|c|}
\hline Jobs & G & $\widetilde{\mathbf{H}}$ \\
\hline$\beta$ & $\langle 50,2,2\rangle$ & $\langle 32,2,2\rangle$ \\
2 & $\langle 38,1,1\rangle$ & $<7,1,1\rangle$ \\
3 & $<41,1,1\rangle$ & $<30,1,1\rangle$ \\
5 & $\langle 34,2,2\rangle$ & $<6,1,1\rangle$ \\
\hline
\end{tabular}

Apply Johnson's technique, the sequence we find

$$
\mathrm{S}_{1}=
$$

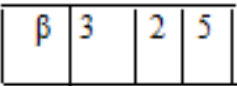

or

$1,4,3,2,5$

Other possible sequence

$S_{2}=4,1,3,2,5$ 


\section{B. VALIDITY of model and to find total elapsed time:}

$\underline{\text { For first sequence } \mathrm{S}_{1} \text {, we have, }}$

\section{Table 5:}

\begin{tabular}{|l|c|c|c|c|}
\hline Jobs & $\mathbf{M}_{1}$ & $\mathbf{M}_{2}$ & $\mathbf{M}_{3}$ & $\mathbf{M}_{4}$ \\
& $\mathbf{I n}$ - out & In - out & In - out & In - out \\
\hline 1 & $(0,0,0)-(16,2,2)$ & $(16,2,2)-(29,2,2)$ & $(29,2,2)-(37,2,2)$ & $(38,2,2)-(45,2,2)$ \\
4 & $(16,2,2)-(31,2,2)$ & $(31,2,2)-(45,2,2)$ & $(45,2,2)-(56,2,2)$ & $(56,2,2)-(64,2,2)$ \\
3 & $(31,2,2)-(49,2,2)$ & $(49,2,2)-(62,2,2)$ & $(62,2,2)-(72,2,2)$ & $(72,2,2)-(79,2,2)$ \\
2 & $(49,2,2)-(66,2,2)$ & $(66,2,2)-(78,2,2)$ & $(78,2,2)-(90,2,2)$ & $(90,2,2)-(96,2,2)$ \\
5 & $(66,2,2)-(80,2,2)$ & $(80,2,2)-(91,2,2)$ & $(91,2,2)-(100,2,2)$ & $(100,2,2)-(106,2,2)$ \\
\hline
\end{tabular}

For sequence $\mathrm{S}_{2}$, we have

Table 6:

\begin{tabular}{|l|c|c|c|l|}
\hline Jobs & $\begin{array}{c}\mathbf{M}_{1} \\
\text { In - out }\end{array}$ & $\begin{array}{c}\mathbf{M}_{2} \\
\text { In - out }\end{array}$ & $\begin{array}{c}\mathbf{M}_{3} \\
\text { In - out }\end{array}$ & $\begin{array}{l}\mathbf{M}_{4} \\
\mathbf{I n} \text { - out }\end{array}$ \\
\hline 4 & $(0,0,0)-(15,1,1)$ & $(15,1,1)-(29,2,2)$ & $(29,2,2)-(40,2,2)$ & $(40,2,2)-(48,2,2)$ \\
1 & $(15,1,1)-(31,2,2)$ & $(31,2,2)-(43,2,2)$ & $(43,2,2)-(51,2,2)$ & $(51,2,2)-(56,2,2)$ \\
3 & $(31,2,2)-(49,2,2)$ & $(49,2,2)-(63,2,2)$ & $(63,2,2)-(73,2,2)$ & $(73,2,2)-(80,2,2)$ \\
2 & $(49,2,2)-(66,2,2)$ & $(66,2,2)-(78,2,2)$ & $(78,2,2)-(87,2,2)$ & $(87,2,2)-(93,2,2)$ \\
5 & $(66,2,2)-(80,2,2)$ & $(80,2,2)-(91,2,2)$ & $(91,2,2)-(100,2,2)$ & $(100,2,2)-(106,2,2)$ \\
\hline
\end{tabular}

Hence, the optimal sequence of the said problem $S_{1}=(1,4$, $3,2,5)$

The minimum total elapsed time $=(106,2,2)$

$\therefore$ Idle time on Machine $1=(106,2,2)-(80,2,2)=(26,2,2)$

Idle time on Machine $2=(15,1,1)+(2,2,2)+(6,2,2)+(3,2$, 2) $+(2,2,2)=(28,2,2)$

Idle time on machine $3=(29,2,2)+(3,2,2)+(8,2,2)+(5$, $2,3)+(4,2,2)=(49,2,2)$

Idle time on machine $4=(40,2,2)+(3,2,2)+(17,2,2)+$ $(7,2,2)+(7,2,2)=(74,2,2)$

Utilization time of Machine $1=(80,2,2)$ hours

Utilization time of Machine $2=(91,2,2)-(28,2,2)=(53,2$,

2) hours

Utilization time of Machine $3=(100,2,2)-(49,2,2)=(51$,

2,2 ) hours

Utilization time of Machine $4=(106,2,2)-(74,2,2)=(32$,

$2,2)$ hours

\section{CONCLUSION}

Fuzzy scheduling is of excessive use for the effective application in real time events. In this paper we have investigated the 3 stages specially structured flow shop scheduling with uncertain parameters. A new technique using fuzziness index function has been proposed to minimize the total pass by time where processing times of machines are fuzzy in nature. The validity of the said model is being examined with numerical illustration and through in-out table. The study can be extended for high inventory cost between more than three machines and more constraints can be added to wider the problem.

\section{REFERENCES}

1. Johnson S.M. (1954), "Optimal two and three stage production schedule with set times included." Naval Research logistics quarterly, 1(1) 61-68.

2. Gupta J.N.D. \& Dudek (1971), "Optimality criteria for flow shop schedule" AIIE transactions 3 (3) 199-205.

3. Maggu P.L. \& Das G.(1977), "Equivalent job block in job scheduling", Operation Research vol 14(4) pp 277-281

4. Singh T.P. (1985),"On 2 x n flow shop problem involving job block, transportation time, arbitrary time and break down machine times. "PAMS" Vol- XXI (1-2)

5. Mccahon S. and Lee E.S. (1990), "Job sequencing with fuzzy processing times," Computer and mathematics applications, Vol 19(7) pp. 294-301.

6. Ishibuchi H and Lee. K.H. (1996), "Formulation of fuzzy flow shop scheduling problem." Proceedings of IEEE International Conference on Fuzzy System pp 199-205.

7. Hong T. and Chuang T. (1999), "New triangular Fuzzy Johnsons Algorithm." Computer and Industrial Engg. Vol 36(1) pp. 179-200.

8. Sayed Reza Hejari, SaeedEmami, Ali Akam (2009), "A Heuristic Algorithm for minimizing the expected make span in two machine flow shops with fuzzy processing times." Journal of Uncertain Systems, Vol 3(2) 114-122.

9. Yager R.R. (1981) “A procedure for ordering fuzzy subset of unit interval.” Information sciences, 24 pp. 143-161.

10. Ming Ma, Friedman, A. Kandel (1999). "A new fuzzy arithmetic,' Fuzzy Sets and Systems Vol 108 pp 83-90.

11. Singh T.P, Sunita and Praveen Ailawalia(2008), "Refer motion of Non-fuzzy Scheduling using concept of fuzzy Processing time under job - block", International conference on Intelligent System \& Network pp 322-324.

12. T.P. Singh \& Sunita (2009) "Fuzzy Flow Shop Problem on 2 Machines with single transportation facility: A Heuristic Approach.” Aryabhatta J.Y. Maths\& Info Vol (1-2) pp 38-46.

13. T.P. Singh \& Sunita Gupta (2010), "An $\alpha$-cut approach to Fuzzy Processing Time on 2 machine flow shop scheduling." Aryabhatta Journal of Mathematics \& Informatics, Vol 2 (1) pp 35-44.

14. T.P. Singh \& Indira Vij (2007) "Minimize Rental Cost of machines in $\mathrm{m}$ stage scheduling with job-block concept." Reflections Das Era, J. of Mathematical Sciences Vol 2 (4) pp 359-370

15. Menu, T.P. Singh \& Deepak Gupta (2013) “A Heuristic Algorithm for General Weightage job scheduling under uncertain environment." Aryabhatta J. of Maths \&Info Vol 5(2) pp 331-388.

16. T.P. Singh, Meenu Mittal \& Gupta D. (2015) "Tardiness of Jobs and Satisfaction Level of Demand Maker in m stage Scheduling with Fuzzy due time.” Arybhatta J. of Maths \& Info. Vol 7(2) pp 351-358.

17. Namita Aggarwal and Arti Tyagi (2017)“ optimal sequence in fuzzy flow shop scheduling with job - block concept using location index and fuzziness index function technique" Aryabhatta Journal of Mathematics \& Informatics Vol. 9, No. 1, ISSN : 0975-7139, pp: 21- 30.

18. Abbasbandy S. \&Hajjari T. (2009). "A New Approach for Ranking of Trapezoidal Fuzzy Numbers." Computers and Mathematics with Applications, Vol 57 pp 413-419.

\section{AUTHORS PROFILE}

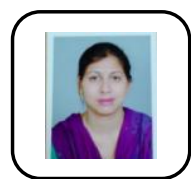

Dr. Arti Tyagi, Ph.D. in Mathematics from MM University, Mullana in 2016 and M.Phil in 2009. She has published 12 papers in reputed journals. She has guided one M.phil. Student in 2017. Her research activities include Queuing model networks, fuzzy systems,

scheduling, .machine learning

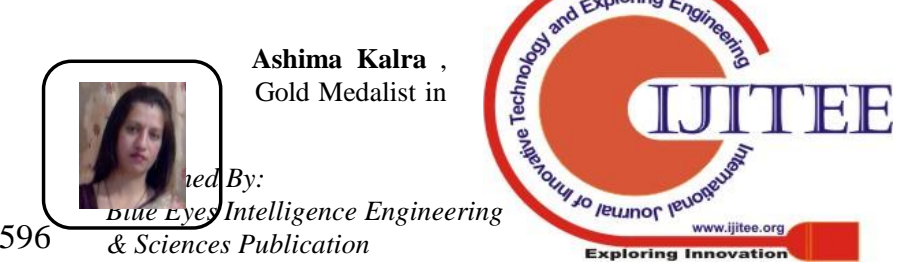


Optimal Sequence in General flow shop with Job block criteria using Fuzzy index Technique

B Tech in Electronics from Kurukshetra University, Kurukshetra in 2003 .Received M.Tech degree from Punjab Technical University, Kapurthla (Punjab)in 2008 and pursuing $\mathrm{PhD}$ from Punjab Technical University , Kapurthla (Punjab )in the field of soft Computing. She has published more than 25 papers in reputed journals and 3 book chapters in Springer series. Her research activities include designing model identification using neural networks, fuzzy systems, supervised learning .machine learning. Lifetime IEEE member and has been serving as a fellow member of IEEE Delhi section, India. Organized 3 IEEE international conferences as a chairperson.

Dr.Cheshta kashyap, Ph.D in Finance and Human Resource,M. Phil in Management in 2008,M.Com in 2010,M.B.A in 2004.She has Published 6 papers in reputed journals.She presented paper at IIT Rurkee in 2014 .Her research activities inculcate Stock Market,Pay for Performance,Finance. 